\title{
Teachers Exploring Mobile Device Integration: A Case Study of Secondary Teachers' Responses to iPads in the Classroom
}

\author{
Stella Erbes, Steven Lesky, and Joshua Myers \\ Pepperdine University, Malibu, CA, USA
}

\author{
stella.erbes@pepperdine.edu; steven.lesky@pepperdine.edu; \\ joshua.myers@pepperdine.edu
}

\begin{abstract}
This qualitative study seeks to understand and resolve the difficulties that teachers encounter when integrating mobile devices in classrooms. To address the issue of teacher receptiveness, three undergraduate researchers collaborated with an education professor in spring 2012 to complete a qualitative study with a two-fold purpose: 1) to investigate how two secondary teachers in an independent school responded when adopting a class set of iPads throughout one school cycle (six school days); and 2) to elucidate what a school could do better to support teachers who are piloting mobile device integration. Although previous studies have commonly focused on the impact of 1:1 programs on student achievement, this study focuses on the role of the instructor when designing and delivering instruction with or without iPads. Qualitative data were collected and recorded after a series of observations and interviews with the teachers and the information technology director. All interviews were roughly transcribed and coded systematically so that patterns could be noted. Results found that both instructors commented about their instructional philosophy, instructional objectives, technology support, teacher efficacy, and classroom. At the conclusion of the experiments, the teachers had favorable impressions of the technology, despite initial misgivings and early technical issues.
\end{abstract}

Keywords: iPad, educational technology, 1:1, BYOD, teacher efficacy, instructional philosophy, teacher training, professional development, technology support, technology integration

\section{Introduction}

Technology has been integrated into society at an exceptional rate, and schools are not immune to the expanded use of mobile devices in classrooms. Smith and Santori (2015) note that schools embraced the iPad after the Apple Corporation introduced the device, and three years later, edu-

(CC BY-NC 4.0) This article is licensed to you under a Creative Commons Attribution-

NonCommercial 4.0 International License. When you copy and redistribute this paper in full or in part, you need to provide proper attribution to it to ensure that others can later locate this work (and to ensure that others do not accuse you of plagiarism). You may (and we encourage you to) adapt, remix, transform, and build upon the material for any non-commercial purposes. This license does not permit you to use this material for commercial purposes. cational institutions purchased 8 million iPads globally, while American schools were responsible for buying 3 million iPads. Chandler and Tsukayama (2014) also recognize that worldwide spending for classroom tablets has surged by $60 \%$ since 2013 . Grant, Tamim, Sweeney, Ferguson, and Jones (2015) confirm that mobile computing devices "are becoming increasingly ubiquitous in society, particularly with the current generation of students" ( $p$. 32). In today's technological culture, growing percentages of K-12 students own and use mobile de- 
vices, and this trend has greatly impacted the 21 st-century learning environment. Therefore, schools face the decision of whether to embrace the use of mobile devices in classrooms or restrict their presence altogether. Educational institutions in the K-12 sector are considering 1:1 programs and "BYOD" (Bring Your Own Device) policies, but such programs are more easily adopted in private, affluent schools that have more resources and smaller class sizes. However, even in these smaller, more wealthy schools, teachers are often inadequately prepared to integrate mobile devices into their classrooms; as a result, they feel apprehensive about and resistant to employing these technologies. These misgivings can lead teachers to feel negative toward technology in general.

The question then arises: What can schools do to assuage teachers' fears and assist them to successfully roll out a 1:1 iPad program? Studies related to the integration of mobile devices are plentiful, but the majority of them focus on how these devices affect student achievement. Research that addresses the instructor's role in adopting such innovations is remarkably scarce. Elements such as developing teacher self-efficacy, creating a clear vision for professional development, and holding regularly scheduled teacher trainings are vital to the successful integration of mobile technology in the classroom, yet they are often overlooked or not seriously addressed when schools adopt a 1:1 or BYOD program. To address this issue of teacher receptiveness, three undergraduate researchers collaborated with an education professor to complete a qualitative study with a two-fold purpose: 1) to investigate how two secondary teachers in an independent school responded when integrating a class set of iPads into their instruction; and 2) to elucidate what a school could do better to provide support for teachers who are integrating mobile devices in the classroom.

\section{Conceptual Foundations}

As technological innovations continue to progress, educators will be provided with more opportunities to incorporate technology into their pedagogies. Conducting a meta-analysis of current perspectives and applications of mobile learning tools, Keskin and Metcalf (2011) claimed that mobile learning "has attracted a great deal of attention from researchers in different disciplines who have realized the potential to apply mobile technologies to enhance learning" (p. 202). However, most studies have been limited to investigating how technology impacts students' achievement and learning experiences (Hargis, Cavanaugh, Kamali, \& Soto, 2014; Jahnke \& Kumar, 2014; Liu et al., 2014; Mango, 2015) rather than how technology affects the role of the teacher. Research on mobile devices has recently shifted its focus from examining how students benefit from software (i.e., apps) and mobility to investigating how teachers can facilitate and maximize students' learning in these technology-enhanced environments (Mouza \& Barrett-Greenly, 2015; Ruggiero \& Mong, 2015). Such studies are revealing that the success of mobile learning rests not only upon the technological literacy of teachers, but also upon their ability to shape student learning with the web of tools that is available in 21st-century classrooms (Meyer, 2013). Therefore, more empirical research is needed to understand how teachers perceive the challenges and potential of mobile device integration and how instructors successfully adopt this newfound pedagogy.

Given most teachers' lack of experience with and inadequate preparation for integrating mobile learning into their classrooms, strategic research-based professional development is imperative when schools consider 1:1 and BYOD program adoption (Mouza \& Barrett-Greenly, 2015). Ertmer and Ottenbreit-Leftwich (2010) argue that "time and effort should be devoted to increasing teachers' confidence for using technology, not just to accomplish administrative and communicative tasks, but to achieve student learning objectives" (p. 5). With consistent systematic training and peer support, teachers can increase their confidence regarding integrating mobile technologies and optimize their instructional value in their classrooms (Mouza \& Barrett-Greenly, 2015; Psiropoulos et al., 2016). By properly addressing educators' concerns and enhancing their skill 
sets through effective professional development programs, classroom teachers can begin to shift their focus from technology to pedagogy (Ruggiero \& Mong, 2015). In doing so, educators can learn how to best harness the full potential of mobile devices to maximize student learning.

\section{Method}

\section{Study Context}

This qualitative study took place in May 2012 at an independent school in southern California. This elite, private school charges a tuition rate of $\$ 28,000$ per academic year and boasts of a low student-to-teacher ratio (13:1) in its community of 1,400 students (grades 5-12). One female middle school English teacher in her first year of teaching (age 22) and a male history teacher in his second year of teaching (age 23) participated in the study. The school was purposefully selected for this research because it was considering the adoption of a mobile device program, and because the teachers were eager study participants who are alumni from our university. A small sample size was intentionally selected in hopes of revealing the intricacies of the mobile device adoption from two case studies, rather than simply collecting general information from a larger group. Also, the small sample size and easy accessibility to the two teachers offered the greatest potential to uncover meaningful experiences given the brief time frame allotted for this internally supported, summer research project. In the future, we hope to be able to devote more time and materials to the study and to expand it to include more participants, including older and more experienced teachers.

\section{Data Collection Methods}

The research team borrowed one class set of first-generation iPads from a local university, and the two instructors used the devices with all five sections of their classes for one school cycle (a cycle consists of five class meetings within a six-day period). Teachers rotated iPads so that each section had several experiences learning with or without the devices. To help monitor student use of the iPads, an undergraduate researcher created a formal check-out log for the devices, along with individual Apple IDs for each device.

Researchers using an interview guide conducted three formal interviews with each instructor. A pre-study interview asked questions assessing the instructor's technological preconceptions before device integration (see Figure 1). A mid-study interview asked questions regarding the instructors' experiences while teaching with iPads and inquired about whether they had experienced any changes in their feelings about mobile device integration (see Figure 2). A post-study interview assessed the instructors' return to instruction without iPads and their final sentiments on the role of technology in the classroom (see Figure 3). The investigation also included participant observation with qualitative field notes of classroom instruction during the course of the study, as well as a supplemental interview with the school's information technology director (see Figure 4). All interviews took place in the participants' natural work settings - their classrooms or office. 
Participant Pre-Study Interview Guide

1. How would you assess your current level of proficiency with technology?

What is your instructional philosophy regarding the role and use of technology in the classroom?

How would you describe your current attitude toward the one-to-one device integration movement?

4. What is your attitude toward adopting iPads in your own classroom? What are your fears, goals, or other aspirations for the study?

5. How are you planning on using the iPad in your classes? What units of study will you cover, and what activities and curriculum will the devices supplement?

6. How would you describe the current technological climate of your workplace-both immediately within your department and within your school as a whole?

What has been your administration's standpoint toward technology in the classroom? What has been their role in the adoption of new technology?

Figure 1. Pre-Study Teacher Interview Guide

Participant Mid-Study Interview Guide

1. How would you describe your overall experience using iPads in your classroom?

2. What did you find most challenging about integrating iPads in your classroom?

3. Can you describe some of the positive outcomes you feel came from integrating the devices into your curriculum? Are there any specific examples that come to mind?

4. How did your students respond to iPad-integrated lessons?

5. Do you feel your personal investment toward integrating iPads in you classroom equaled its return? Why or why not?

6. How much extra work was required to integrate the iPad into your teaching style? Can you provide an example of something you have had to change in any of your courses?

\section{Figure 2. Mid-Study Teacher Interview Guide}

\section{Participant Post-Study Interview Guide}

In comparison to your traditional teaching style and technology, do you believe the iPad has enabled you to be more or less effective as an educator? Can you provide an example of how you feel the effectiveness of your teaching style has been altered?

Do you think the iPad is a valuable tool in the classroom that it is worth the effort to 2. integrate it into your teaching style and curriculum, and also worth the cost to the school?

3. How would you describe the response of your students during the migration back to non-iPad based instruction?

4. Did your students exhibit a particular preference toward iPad or traditional instruction? What did you notice?

5. How has your opinion of the one-to-one movement been strengthened or altered in light of this study?

Has your instructional philosophy regarding the use of technology changed as a result of this study? Why or why not?

Figure 3. Post-Study Teacher Interview Guide 


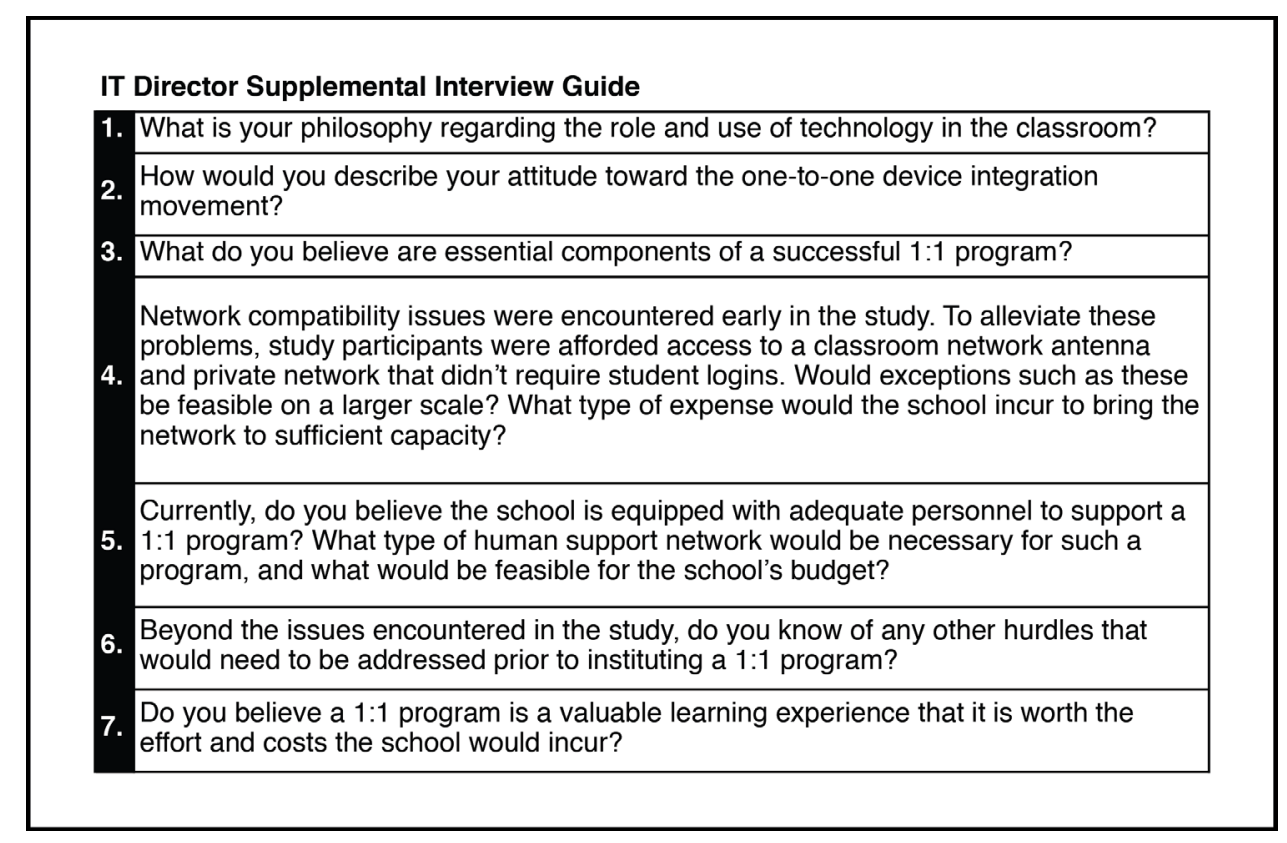

Figure 4. Information Technology Director Interview Guide

\section{Data Analysis}

Like Smith and Santori (2015), this qualitative study adopted a grounded theory approach, or portraiture methodology, which allowed our research team to collect data in its natural setting and analyze it systematically to reveal repeated themes. By adopting this method, we were able to draw conclusions from rich and detailed interview responses gathered from our informants, which described and highlighted the potential growth and success that teachers could experience from iPad integration. One undergraduate researcher engaged in participant observation in the classes of our teacher participants during the course of the study, conducted and recorded all interviews, and roughly transcribed the audio data. The transcriptions were later used for a comparative analysis and produced patterns, or "codes," that captured the participants' overall perceptions of mobile device integration in classrooms (see Figure 5).

Various themes related to the teachers' instructional philosophies, instructional objectives, technology support, teacher efficacy, and classroom management naturally emerged from the interview data analysis. It was clear from the interview data that the experience of integrating iPads into their classrooms prompted both the teachers and the information technology director to consider why educators would adopt mobile devices, how the devices could support instructional objectives, and how the technological infrastructure could support the implementation of the devices in schools. Additionally, the study allowed both teachers the opportunity to execute iPad integration, and this authentic experience revealed issues of teacher efficacy that organically arose after they had adopted new strategies in the classroom. This corroborated Ruggiero and Mong's (2015) claims that valuable information will be revealed when teachers are allowed to interact with mobile devices in their natural instructional environments. Figure 6 highlights how the transcribed interview data was analyzed for patterns and how those patterns were coded. 


\begin{tabular}{|l|l|}
\hline Code & Subcode / Associated Pattern in Participant's Interview Response \\
\hline Instructional Philosophy & $\begin{array}{l}\text { Instructional philosophy regarding technology in education } \\
\text { Attitudes toward iPad/1:1 integration } \\
\text { iPad instruction vs. traditional instruction }\end{array}$ \\
\hline Instructional Objectives & Specificity of goals/tasks to be accomplished with the iPad \\
\hline Tech Support & Technological infrastructure \\
\hline Teacher Efficacy & $\begin{array}{l}\text { Proficiency with technology } \\
\text { Instructional support } \\
\text { Teacher perception of effectiveness (teacher) } \\
\text { Teacher perception of effectiveness (student) } \\
\text { Desire to further explore technological curriculum } \\
\text { The role of one's age in the adoption/integration of technology } \\
\text { Preparation of iPad-driven curriculum }\end{array}$ \\
\hline Classroom Management & Classroom management \\
\hline
\end{tabular}

Figure 5. Interview codes and subcodes

\section{Q: How would you assess your current level of proficiency with} technology?

A: I'm relatively proficient $1-$ especially due to my youth...

1 Code: Teacher Efficacy
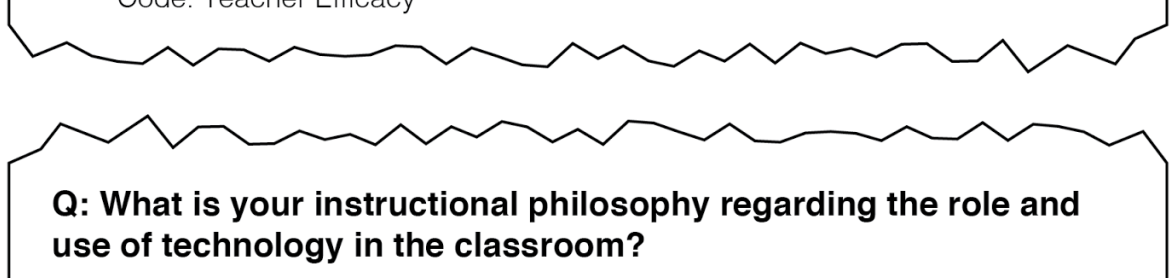

A: I think it is often overrated. ${ }^{2}$ Teachers use it for pizazz...

2 Code: Instructional Philosophy

\section{Figure 6. Coding Sample}

\section{Results}

Results indicated a high frequency of responses related to instructional philosophy, instructional objectives, technological support, teacher efficacy, and classroom management. These emergent themes were congruent to those found in the empirical studies reviewed in the research literature discussing teachers' mobile device integration experiences (Grant et al., 2015; Mouza \& BarrettGreenly, 2015; Psiropoulos et al., 2016). When teachers from our study overcame external obsta- 
cles (i.e., lack of training and technology devices) and internal barriers (i.e., attitude toward technology, low self-efficacy) that impeded them from fully embracing mobile devices in the classroom (Ruggiero \& Mong, 2015), then the stage was set for both teachers and students to actively engage in the teaching and learning process using mobile devices.

In our study, when given a set of iPads to use with their respective classrooms, neither teacher knew how to deploy the iPads, which included creating Apple IDs for each device, ensuring strong Wi-Fi connectivity for the iPads, and downloading educational apps for classroom instruction. Additionally, the instructors were not familiar with iPad applications that could be easily be integrated into their instruction. As a result, both educators relied heavily on the expert knowledge and experience of our undergraduate research team to help them with the setup and use of iPads in the classroom. Mouza and Barrett-Greenly (2015) documented similar experiences among teachers in their study, who relied on students for ongoing technical support when integrating mobile devices.

The researchers found that sporadic needs for troubleshooting led to positive learning opportunities in which students were able to share their technical knowledge to assist teachers. These situations created a collaborative teaching and learning environment where a model of co-constructed learning replaced the traditional process of a teacher exclusively directing instruction. This experience promoted confidence in the students and facilitated technological support and classroom management. Both instructors in our study showed significant alterations and improvements to their respective pedagogies and efficacy with technology after multiple experiences with and without the devices in their classrooms. Instructors reported that the experiences with the iPads transformed their initial feelings of caution and reluctance into confidence and ambition.

\section{Middle School Teacher: Wary Efficacy Gives Way to Excitement}

An ambitious, young English teacher, this participant was enthusiastic and open to integrating technology into her classroom instruction, but she encountered hardships upon realizing that her knowledge of and abilities with the mobile devices were limited. Fortunately, she possessed a calm and patient disposition and had created alternative teaching plans for her students in case the technology malfunctioned. Using iPads, the middle school instructor taught grammar and vocabulary lessons, employing applications like Whiteboard and Socrative. Both applications helped students provide feedback to the educator. Whiteboard was used as a personal writing pad for students to create and collaborate, while Socrative was used for its question-and-answer capabilities and polling features.

Despite her openness to the idea of integrating technology, this teacher's knowledge and experience with mobile device instruction was limited. Her middle school students' experiences with iPads exceeded her level of expertise, which left her vulnerable to criticism of her inadequacies. However, the middle school teacher was open to learn from her students. For example, one of her students introduced her to Nearpod, an iPad application that she had heard of prior to the study and later incorporated into her daily instruction. This experience challenged traditional authoritarian teacher-to-student roles, and the co-construction of knowledge created a learning opportunity for both the instructor and her pupil.

At the end of the study, the teacher felt that the benefits of using iPads had been worth the effort she put into modifying her lessons. As the study progressed, her students had become more excited about using the devices, and their enthusiasm became a source of empowerment. This study participant experienced noticeable change in her personal efficacy and became more confident in her abilities to implement technology in her classroom (see Figure 7). 


1. Pre-Study Interview
\begin{tabular}{|l|l|}
\hline Code & Participant Response \\
\hline Instructional Philisophy & $\begin{array}{l}\text { "I believe technology is at the forefront of education. It's the way things } \\
\text { are going, and you can't fight it." }\end{array}$ \\
\hline Teacher Efficacy & $\begin{array}{l}\text { "My fear with having iPads is that I would want to see them being used } \\
\text { effectively." }\end{array}$ \\
\hline
\end{tabular}

\begin{tabular}{l} 
2. Mid-Study Interview \\
\begin{tabular}{|l|l|}
\hline Code & Participant Response \\
\hline Tech Support & $\begin{array}{l}\text { "Getting everyone set up on the network at first was challenging. When } \\
\text { I didn't have support I told my students, "I don't know what to tell you." }\end{array}$ \\
\hline Classroom Management & "It was challenging because they were really excited, and it was difficult \\
to work with their level of excitement."
\end{tabular} \\
\hline
\end{tabular}

3. Post-Study Interview

\begin{tabular}{|l|l|}
\hline Code & Participant Response \\
\hline Teacher Efficacy & $\begin{array}{l}\text { "I definitely think it is worth my time to integrate the iPad into my } \\
\text { curriculum." }\end{array}$ \\
\hline Classroom Management & $\begin{array}{l}\text { "My students were engaged and wanted to do whatever we were doing. } \\
\text { They wanted to get the answers right. They wanted to come to class. } \\
\text { They didn't want to leave." }\end{array}$ \\
\hline
\end{tabular}

Figure 7. Notable Responses from Middle School Teacher

\section{High School Teacher: Skeptic Remains Hopeful}

Prior to the study, our high school teacher participant was reluctant to implement technology just for the sake of adding technology in the classroom. "If you're going to use technology, it has to serve a clear objective that you've defined beforehand. It's just like any other lesson. It shouldn't be used for the pizazz unless the pizazz assists that objective," he said. This instructor valued clear instructional objectives, technological support, and teacher efficacy (see Figure 8). His skepticism toward technology integration was derived from a past experience at his institution when faculty had been provided with interactive whiteboards but given little to no training on how to use them effectively. Even so, the teacher recognized the value of updating his teaching style with relevant technological tools available in today's digital learning environment, and this history teacher was particularly interested in using the iPad to amplify his teacher-directed, PowerPoint-based lessons about the Reformation and political propaganda.

Through the Nearpod app, the instructor was able to integrate polling and assessment features into his direct instruction to gather instantaneous student feedback. The high school teacher also used other applications, including Popplet, an interactive application used to strengthen visualbased learning, and Edmodo, an application boasting collaborative features such as file sharing and user submission capabilities. He felt that using these apps increased his efficacy when combining technology with his instructional philosophy and pedagogical style. 
1. Pre-Study Interview

\begin{tabular}{|l|l|}
\hline Code & Participant Response \\
\hline Teacher Efficacy & $\begin{array}{l}\text { “My goal is to be relatively neutral with wanting to see iPad-centered } \\
\text { lessons be better than non-iPad teaching." }\end{array}$ \\
\hline Teacher Efficacy & $\begin{array}{l}\text { "There's been significant frustration at our school with SMART products } \\
\text { because the school bought everyone SMART boards and people don't } \\
\text { know how to use them.” }\end{array}$ \\
\hline
\end{tabular}

2. Mid-Study Interview

\begin{tabular}{|l|l|}
\hline Code & Participant Response \\
\hline Classroom Management & "I was afraid of losing my students quicker than I normally would. The \\
device is a learning tool but it's also a potential distraction."
\end{tabular}

3. Post-Study Interview

\begin{tabular}{|l|l|}
\hline Code & Participant Response \\
\hline Instructional Philisophy & $\begin{array}{l}\text { "Technology can be used to improve learning. I think it has to be done } \\
\text { intentionally and with a degree of experimentation." }\end{array}$ \\
\hline Teacher Efficacy & $\begin{array}{l}\text { "Using the iPad has helped me to become a more effective teacher. } \\
\text { The device provides instantaneous feedback that you can't achieve by } \\
\text { traditional methods." }\end{array}$ \\
\hline
\end{tabular}

Figure 8: Notable Responses from High School Teacher

Midway through the study, the high school teacher was impressed with the increased engagement of his students, although he had originally expressed fear that his students would become distracted by these new devices, which would hamper his ability to manage effectively the classroom. At the conclusion of the research, this participant stated that integrating iPads in his classroom instruction was "definitely worth the effort" and believed that a 1:1 program could positively impact one's teaching style and improve student learning.

\section{Interview with Information Technology Director}

Our research team interviewed the information technology director to inquire about his perspective on implementing a 1:1 or BYOD program schoolwide. The director believed that technology integration in classrooms was valuable; however, "it shouldn't necessarily be the focus of teaching - rather, it should be a tool to better teach students and reach them in different ways." This response echoes Meyer's (2013) claims that mobile devices should not stand alone as learning tools but should be considered part of the web of tools that teachers employ to shape learning. In fact, the key to effective use of such technology is to focus on student learning and not solely on the technology.

When asked about essential components of a successful mobile device implementation, the director responded, "The first and most important is training - training for the faculty on how to use the device and how to troubleshoot." Additionally, the director viewed technological support as a critical resource needed when adopting a mobile device program. "It's necessary to have adequate personnel to fix problems and replace anything broken so that a class (or even a single student) 
Mobile Device Integration: Case Study of Secondary Teachers' Responses

isn't impacted by hardware malfunction." Providing ongoing teacher development and staff specifically hired to coordinate and maintain technical needs are crucial steps that schools must consider to effectively implement programs with mobile learning devices (Mouza \& Barrett-Greenly, 2015; Psiropoulos et al., 2016; Ruggiero \& Mong, 2015).

\section{Discussion}

Our study produced three significant findings that reveal how teachers feel when integrating a 1:1 iPad program. These findings will be helpful to other educators and institutions that seek to adopt similar initiatives.

\section{Teachers Feel Doubtful About Using Technology When It Doesn't Work Properly and Confident When They Receive Help from Tech Support Staff}

Working with a school's information technology department to ensure strong Wi-Fi connections for iPads is critical in the setup stage of an iPad learning project (Grant et al., 2015). Our middle school English teacher recalled that "getting everyone set up on the network at first was challenging. It was hectic getting everyone hooked up and wired onto the network, but we were able to troubleshoot." Students watch to see how a teacher will respond to and troubleshoot tech problems, and this example of teacher efficacy can positively or negatively impact student achievement. The middle school teacher continued:

This study has helped me to think more about the logistic[al] side of such a program. Twenty iPads aren't going to show up in your classroom with everyone knowing how to use them. 1:1 requires a significant amount of troubleshooting and looking prepared even though you're unprepared. You have to problem solve on the spot. You need to find help from other people; you need to constantly change things. I had never really thought about that before. I used to think "if we had iPads, we could do ," but there's more stuff involved.

Given that our study was performed on a small scale using only two teachers, it was easier to have the tech support department on hand to assist the teachers. However, if launching a schoolwide 1:1 program, these challenges would be more difficult to overcome and could create a negative tone around iPad integration. When planning a successful mobile device program, school systems should provide teachers with adequate technological support (Ruggiero \& Mong, 2015).

\section{Teachers Feel Fearful When Integrating Technology without Proper Training}

Without proper training, teachers are fearful when considering how to integrate iPads successfully in their classrooms. In this study, success of the iPad adoption was due greatly to the training and support that teachers received from our undergraduate research team who helped locate innovative, educational iPad apps, such as Nearpod, Socrative, Edmodo, and Popplet, which could be quickly and easily integrated into classroom instruction. Although both teacher participants described their level of technological knowledge as above average or relatively proficient, both also recognized that there is a steep learning curve when teachers consider adopting appropriate apps and digital tools into one's pedagogy. The middle school English teacher concluded:

Finding apps is hard - the hardest. It was a big change switching from PowerPoint to Nearpod-going from "What did you get on number five?" to "Hold up your answer on the [digital] whiteboard" and getting live feedback on Socrative. The smallest modifica- 
tions make the biggest difference. We switched from "This is how we do things in my class" to "Let's try this."

Expressing a similar sentiment, the high school history teacher commented:

There's a fear factor of integrating technology because as a teacher you start to give up control in ways that you normally don't. Now your students have this device which they can use to go down rabbit holes if they want to. That was scary. You become afraid of losing them quicker than you normally would because the device is a learning tool but it's also a potential distraction.

Teacher training on successful use of digital technology goes a long way to assuage teachers' fears about that technology. If a school sets teachers up for success with a realistic understanding of and expectations for technology in the classroom, teachers' fears can be diminished (Mouza \& Barrett-Greenly, 2015). Intentional professional development and ongoing technological support is crucial so that teachers will feel equipped and confident to integrate iPads or similar technology successfully in their classrooms.

\section{Teachers Feel Hopeful about Future Uses of Technology in the Classroom}

Teachers were hopeful after observing that students' attitudes were positive and enthusiastic towards learning with iPads. Our middle school English teacher reported:

Using iPads was incredibly engaging for all students. [M]y students who aren't fond of English enjoyed it and had fun learning whatever material we were covering. The biggest outcome in my opinion was that every student was engaged. Every day they came to class they would say, "Is today iPad day?" They wanted to use the iPads and they wanted to be here. You would hear them say things like, "This is the best day ever!" and "I love English!" It really made a difference in our learning community in terms of wanting to participate and be engaged.

Similarly, the high school history teacher found:

When used properly, [the iPad] does increase student engagement. We used iPads for a block period (1.5 hours) in history on a Friday afternoon. It was the perfect storm, and my students were crazy because of that. They were thinking of the weekend. We used the iPads and for the first half of the block, I lectured traditionally. In the second half, they created Reformation posters on Popplet. They were all geared into it and stayed engaged until the end of school. They would have stayed longer had I not told them what time it was. Their level of interest was crazy.

Rather than restrict students from using mobile devices in classrooms, schools should embrace these digital tools and educate both teachers and students on how to use technology to increase student engagement (Grant et al., 2015). Mobile devices have the potential to reinvigorate the teaching and learning process for both teachers and students, if they are deployed correctly.

\section{Conclusion}

This study presents helpful insights to schools that are considering mobile device integration. Although certain elements of the project limit the audience's ability to generalize the findings on a larger scale, the results of this empirical research prompt the educational community to consider several valuable points when developing successful 1:1 mobile device programs. 


\section{Limitations and Future Research}

A case study approach was intentionally adopted for this research project, which allowed a deep exploration of the experiences of two secondary teachers who integrated mobile devices into their instruction. Given the limited time frame for the research and the accessibility of resources for this internally supported summer undergraduate research project, our research team believed that case studies would reveal the most meaningful data. However, readers should use caution when generalizing these findings to a wider population given the small number of informants. For future research, the study could be expanded to include more teachers, particularly those who are older, more experienced, and more culturally diverse. In this case, our participants were two Caucasian teachers in their early 20 s, who were in their first or second year of teaching in an affluent, private school. Further investigations could also include students' perspectives, which would broaden our understanding of the ways integrating mobile devices in classrooms affects the traditional roles of teachers and students in schools.

\section{Implications}

In order for schools to build a successful 1:1 iPad program, they must address critical needs in the integration process, which include a strong infrastructure for seamless Wi-Fi connections and strategic and ongoing teacher trainings. The mobile integration process involves overcoming some external barriers, such as acquiring devices and developing reliable wireless connections, as well as establishing a vision for continual professional development to maintain and support the implementation, instruction, creativity, and imagination of the educators who execute the deployment of the devices in their classrooms. One approach to accomplish these goals is for schools to invest in a coordinator of educational technology, who will be dedicated to developing and carrying out faculty training that will support teachers as they learn how to utilize mobile technology in their daily instruction. Ruggiero and Mong (2015) confirmed that "training about technology is most effective when it is contextually based in their own classrooms" and employing an individual for ongoing professional support in schools is invaluable in the mobile integration process (p. 162-163).

Additionally, schools should create an educational technology committee, composed of administrators, faculty, librarians, staff, and students who meet regularly throughout the academic year to discuss the challenges, best practices, and future goals for technology within the school. Accrediting bodies such as the Western Association of Schools and Colleges will look favorably upon efforts such as a strategic plan to continually support and grow the technological knowledge of the faculty and staff. Smith and Santori (2015) encouraged administrators, staff, and teachers "to focus not just on finding apps, but also on maximizing the iPad's potential to support differentiated instruction, visualization of concepts, learner independence and agency, dynamic presentation of content, and collaborative interactions" (p. 183). An educational technology committee is a vehicle that can be used to discuss how all constituents of a school view the role that technology plays in the teaching and learning process.

\section{Final Thoughts}

When key elements such as technical support and a clear vision for professional development are in place to support teachers in the mobile integration process, teachers will retain hopeful attitudes about using technology in the classroom, although the more difficult challenge falls upon the educators themselves. As technology integration becomes increasingly popular, teachers must acknowledge that their role in the classroom is changing. With the adoption of mobile devices such as iPads in schools, teachers cannot remain stagnant and rely simply on textbook-based, direct instruction. Instead, they must revisit and revise their teaching philosophies, expose their vulnerability in the classroom while knowing that their students might possess more technical 
knowledge than they do, and work through the uncomfortable stages of learning new tools to add to their pedagogy. With more experience and a clear vision for ongoing professional development, mobile device integration can encourage teachers to reimagine and refresh their pedagogy.

\section{References}

Chandler, M. A., \& Tsukayama, H. (2014, May 17). Tablets proliferate in nation's classrooms, taking a swipe at the status quo. Washington Post. Retrieved from http://www.washingtonpost.com/local/education/tablets-proliferate-in-nations-class rooms-and-take-aswipe-at-the-status-quo/2014/05/17/faa27ba4 dbbd11e38009-71de85b9c527_story.html

Ertmer, P. A., \& Ottenbreit-Leftwich, A. T. (2010). Teacher technology change: How knowledge, confidence, beliefs, and culture intersect. Journal of Research on Technology in Education, 42(3), 255-284.

Grant, M. M., Tamim, S., Sweeney, J. P., Ferguson, F. K., \& Jones, L. B. (2015, July/August). Teaching and learning with mobile computing devices: Case study in K-12 classrooms. Tech Trends, 59(4), 3245 .

Hargis, J., Cavanaugh, C., Kamali, T., \& Soto, M. (2014). A federal higher education iPad mobile learning initiative: Triangulation of data to determine early effectiveness. Journal of Innovative Higher Education, 39(1), 45-57.

Jahnke, I., \& Kumar, S. (2014). Digital didactical designs: Teachers' integration of iPads for learningcentered processes. Journal of Digital Learning in Teacher Education, 30, 81-88.

Keskin, N. O., \& Metcalf, D. (2011). The current perspectives, theories and practices of mobile learning. Turkish Online Journal of Educational Technology-TOJET, 10(2), 202-208.

Liu, M., Scordino, R., Geurtz, R., Navarrete, C., Ko, Y., \& Lim, M. (2014). A look at research on mobile learning in K-12 education from 2007 to the present. Journal of Research on Technology in Education, 46(4), 325-372.

Mango, O. (2015, January). iPad use and student engagement in the classroom. Turkish Online Journal of Educational Technology-TOJET, 14(1), 43-57.

Meyer, B. (2013, October). iPads in learning: The web of change. Paper presented at the International Association for Development of the Information Society International Conference on Cognition and Exploratory Learning in the Digital Age, Fort Worth, Texas.

Mouza, C., \& Barrett-Greenly, T. (2015). Bridging the app gap: An examination of a professional development initiative on mobile learning in urban schools. Computers \& Education, 88, 1-14.

Psiropoulos, D., Barr, S., Eriksson, C., Fletcher, S., Hargis, J., \& Cavanaugh, C. (2016). Professional development for iPad integration in general education: Staying ahead of the curve. Education Information Technologies, 21(1), 209-228.

Ruggiero, D., \& Mong, C. J. (2015). The teacher technology integration experience: Practice and reflection in the classroom. Journal of Information Technology Education Research, 14, 161-178. Retrieved from http://www.informingscience.org/Publications/2227

Smith, C. A., \& Santori, D. (2015). An exploration of iPad-based teaching and learning: How middlegrades teachers and students are realizing the potential. Journal of Research on Technology in Education, 47(3), 173-185. 


\section{Biographies}

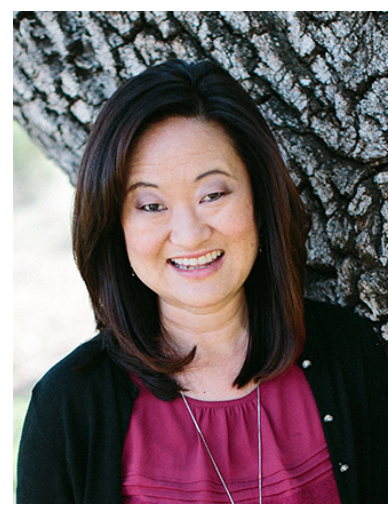

Dr. Stella Erbes, Associate Professor of Teacher Education at Pepperdine University, earned her Ph.D. in educational psychology and Masters degrees in education and Spanish from the University of California at Santa Barbara. Currently, she teaches Instructional Design, Advanced Teaching Methods and Educational Technology. Dr. Erbes' research interests focus on educational technology and teaching methodologies.

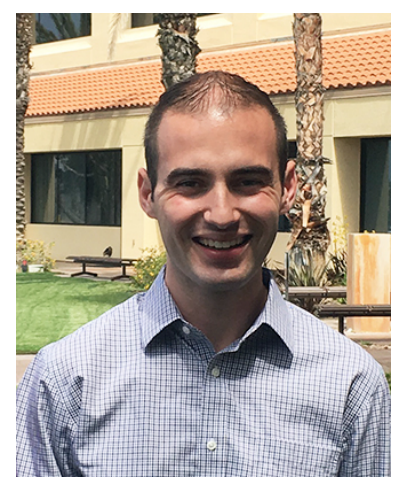

Steven Lesky graduated from Pepperdine University in May 2015 with a Bachelor of Arts in Economics, a Minor in Hispanic Studies, and a CA SB2042 Preliminary Single Subject Teaching Credential. As an undergraduate student, Steven was passionate about the disciplines of learning, research, and educational technology. Steven currently works as an analyst in Pepperdine's Office of Financial Planning while pursuing further education.

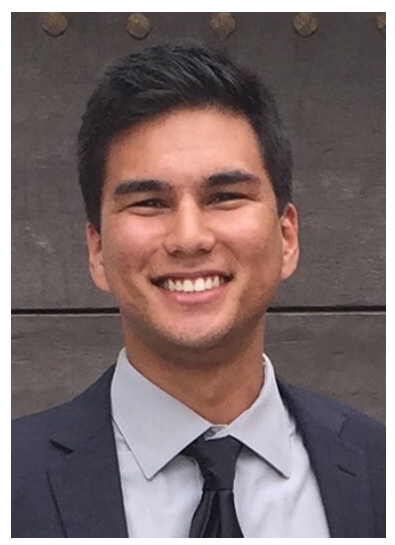

Joshua Myers is in his third year of enrollment at Pepperdine University and is a Computer Science major. Joshua is a standing member of the Lambda Sigma chapter of the Psi Upsilon fraternity in which he has assumed multiple leadership positions. He is also serving in Pepperdine University's Housing and Residence Life organization as a Resident Advisor. Joshua's research interests focus on effective uses of technology. 